\title{
Doença dos Nervos: Sentidos e Representações
}

Illness of the nerves: Sense and representations

Denise Silveira Dutra, Edna Claudia Jorge,

Jacqueline Müllich

Fensterseifer \& Silvia

Virginia Coutinho Areosa

Universidade de

Santa Cruz do Sul
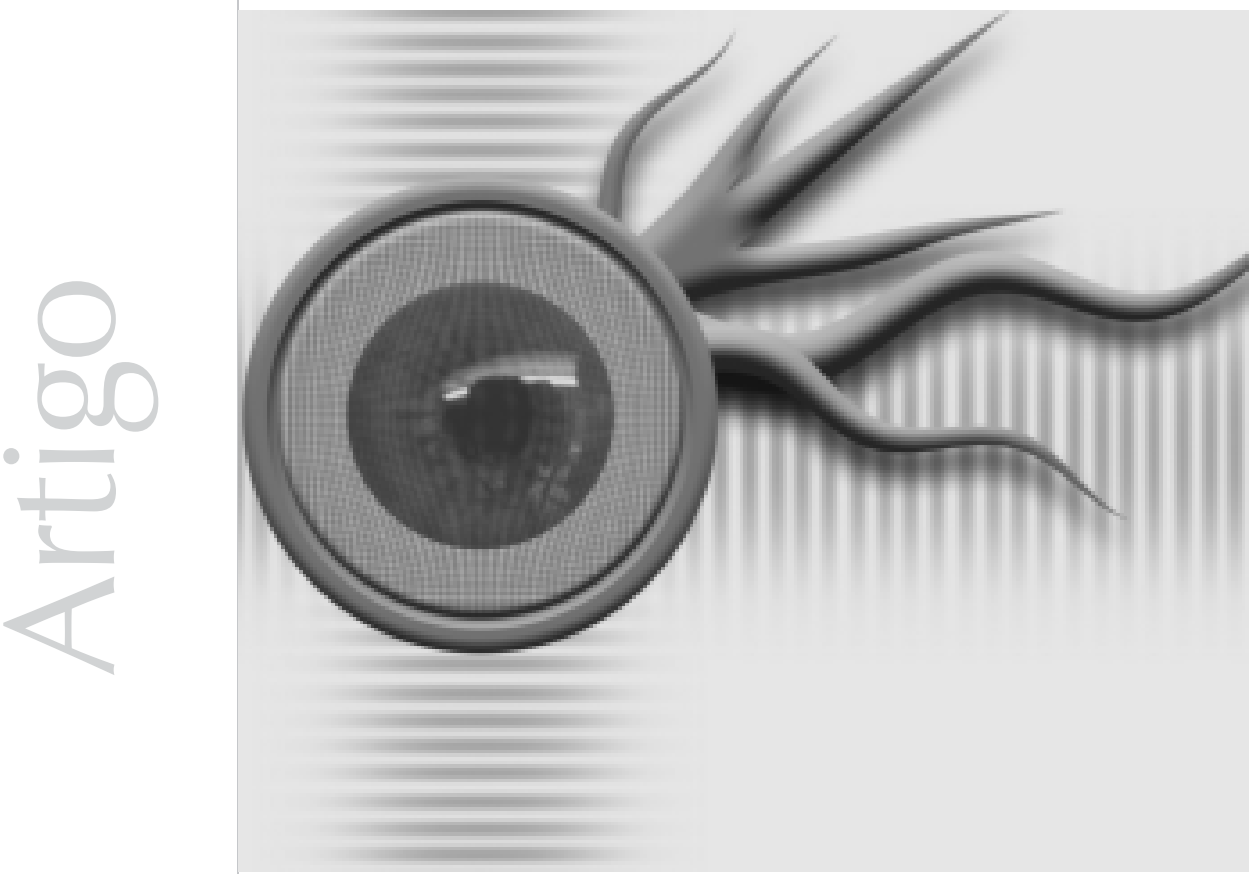


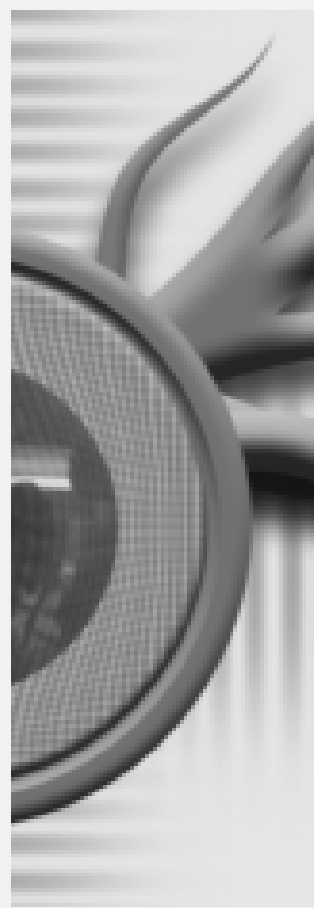

Resumo: Este artigo é o relato de uma pesquisa qualitativa realizada em dois postos de saúde do Município de Santa Cruz do Sul, nos anos de 2003 e 2004, tendo como objetivo desvendar o significado da "doença dos nervos" entre as classes populares. Para tanto, utilizou-se a técnica do grupo focal, organizando-se os resultados em categorias. Foram encontrados diferentes significados para essa doença, como o estranhamento, a infantilização e a perda de identidade da pessoa portadora de sofrimento psíquico.

Palavras-chave: doença dos nervos, sofrimento psíquico, classes populares.

Abstract: This paper reports the findings of a quality research in two health centers in the city of Santa Cruz do Sul in 2003 and 2004. The goal of this research was to determine the real meaning of the illness popularly known as illness of the nerves among the lower social groups. We used the focal group technique and organized the data in categories. We found different meanings for this illness, as estrangement, infantilization and loss of identity of the person complaining of psychic suffering.

Key words: illness of the nerves, psychic suffering, low social groups.

Considerando que cada situação histórica e social evidencia não só conceitos muito próprios do que seja saúde mas também formas muito próprias de apresentação de sintomas e doenças pela humanidade, entendemos legítima a curiosidade e o interesse em pesquisar acerca de uma dada queixa que se apresenta comum atualmente, principalmente entre as classes populares: é a chamada "doença dos nervos".

No decorrer da experiência de estágio em Psicologia comunitária realizado em postos de saúde de bairros da periferia do município de Santa Cruz do Sul / RS, observou-se um alto índice de pessoas que buscavam receitas médicas com prescrição de psicofármacos. Instigadas e, ao mesmo tempo, preocupadas com a situação que não parava de se exibir aos nossos olhos, resolvemos escutar essas pessoas à procura de conhecer os motivos que as levavam a tal busca. Foi então que vimos que a principal justificativa para o uso desses medicamentos correspondia à queixa de sofrerem de doença dos nervos. Pois bem, mas que doença era essa, que assim nomeavam?

Dimenstein (2000) cita que, nas camadas populares, a expressão de conflitos é colocada como "doença dos nervos", materializando-se no corpo, que é o principal veículo de expressão e comunicação de vivências. Esses sujeitos realizam, assim, uma forma de divisão entre corpo e espírito, sendo que a cura significa o desaparecimento do sintoma e o restabelecimento da vida normal; portanto, esse adoecer está situado estritamente no corpo, acreditando-se que a solução esteja no remédio. "O discurso da enfermidade é dotado de sentido na medida em que é afirmado como real para os indivíduos" (Alves \& Minayo, 1994, p. 98).

A partir dessa nova interrogação é que surgiu o interesse em pesquisar as representações 
sociais da "doença dos nervos" nessas comunidades. A escolha da teoria das representações sociais como sustentáculo da pesquisa deveu-se justamente ao fato de estar considerando-se a experiência de vida e a subjetividade dessas pessoas, que estão necessariamente impressas na forma como adoecem e, ainda, na forma como nomeiam sua doença, formas essas compartilhadas pelo grupo social em que estão imersos, de tal modo que a queixa se repetia incansavelmente.

\section{Saúde pública e representações sociais}

A escolha da teoria das representações sociais como sustentáculo da pesquisa deveu-se justamente ao fato de estar considerando-se a experiência de vida e a subjetividade dessas pessoas, que estão necessariamente impressas na forma como adoecem

e, ainda, na forma como nomeiam sua doença, formas essas compartilhadas pelo grupo social em que estão imersos, de tal modo que a queixa se repetia incansovelmente.
Ao pensar-se em saúde pública, faz-se necessária a inserção dos profissionais que nela atuam nas comunidades. A saúde, nessa perspectiva, só é entendida através do conhecimento da realidade em que se quer intervir, seja para sua promoção, seja para prevenção ou assistência ao adoecimento já instalado. Pode-se dizer que o trabalho em saúde pública representa um constante descobrir do que está encoberto pelos comportamentos, pelas queixas, pela tristeza e, por que não, pela alegria singular e coletiva. Muitas vezes, a equipe de saúde pública não tem um tempo necessário para ouvir o paciente, e, para fazê-lo calar imediatamente, existe a alternativa do remédio, com o qual esse sujeito é barrado, alienado do seu próprio desejo, não podendo expressar-se. Com isso, muitos deles já procuram atendimento com o intuito de encontrar soluções mágicas para seus problemas, pedindo um "remedinho" porque sofrem de "doenças dos nervos", que é a maneira que possuem para expressar seu sofrimento.

Problematizando o trabalho do psicólogo nos serviços públicos de saúde, Leite (1997) salienta a necessidade de resgatar o existir enquanto processo nos contextos institucionais, de modo que os discursos dos sujeitos ganhem espaço, expressão e sejam reconhecidos dentro dos serviços.
Entretanto, o que predomina, segundo Weigelt (2001), é justamente o contrário; para a autora, a população não é consultada sobre suas reais necessidades, assim como os profissionais não são consultados sobre os processos de planejamento e gestão dos serviços de saúde.

É desmitificando o poder do saber científico (médico) que se trabalhará a saúde pública, considerando-a também como um direito à cidadania. Como coloca Camargos (1993), se queremos que as pessoas se sintam como cidadãos, é preciso que se sintam como sociointegrantes e, portanto, responsáveis pela sociedade, e isso implica o conhecimento e a idéia que ela tem de si e do mundo.

Até pouco tempo, prevalecia um modelo de saúde baseado única e exclusivamente no saber científico e no assistencialismo, acima da participação social e promoção de saúde. Campos (1994), em seu livro intitulado A Saúde Pública e a Defesa da Vida, contextualizando capitalismo e saúde pública, coloca o quanto o primeiro é incongruente com a segunda.

No capitalismo, predomina a dinâmica da acumulação em dissonância com a necessidade de investimento em melhores condições de vida da população e nas próprias condições de saúde dessa população, haja vista que não são poucos os problemas coletivos gerados pelo crescimento econômico. Isso significa que o crescimento econômico não só desfavorece a necessidade de investimentos em saúde como é, ele próprio, causador de más condições de vida e de adoecimento da população. Diante disso, e, apesar de existir um grande número de projetos ditos sociais, ainda é possível sentir uma tendência à assistência individualizada para que o olhar público evite mirar com efetividade para as condições de saúde do coletivo.

Pouco se estabelece de relação entre o sofrimento e o adoecimento individual com a condição coletiva, e, para que essa condição seja preenchida, é preciso haver participação social e não pura e simplesmente domínio 
econômico. Enquanto as pessoas não se colocarem como cidadãos diante da sua condição de saúde - e, para isso, é preciso que elas tenham voz no espaço público, continuarão à margem dos processos de decisão em torno, inclusive, da sua própria condição individual. E o pior é que talvez nem se perceba isso.

É preciso estar sempre atento ao modo como os fatores sociais, culturais, econômicos e políticos se articulam na vida do indivíduo, seja nas questões do mundo externo ou nas representações internalizadas e carregadas de afeto seja ainda nas representações sociais acerca da "doença dos nervos".

Almeida, Santos e Trindade (2000) afirmam que o termo representação social foi proposto por Moscovici (1984) para considerar o conhecimento do senso comum que, até então, era considerado uma forma de conhecimento "pré-lógico," opondo-se ao conhecimento científico. Moscovici (1961) conseguiu uma forma de estudar cientificamente o "senso comum".

De lá para cá, conforme Lhullier (1997), a teoria das representações sociais (RS) tem significado, para muitos psicólogos sociais, a possibilidade mais promissora para a superação da dicotomia indivíduo / sociedade.

Para Almeida, Santos e Trindade (2000), o objetivo do estudo da teoria das representações sociais (RS) é poder compreender o processo de construção social da realidade. Os autores citam Jodelet (1984), que afirma que as RS são conhecimentos socialmente elaborados e compartilhados, tendo como objetivo a compreensão e a explicação de fatos e idéias que fazem parte do universo das pessoas pesquisadas, havendo, assim, maior conhecimento prático da realidade que os compõe e que os cerca.

Para investigação das RS, conforme colocam Oliveira e Werba (1998), não existe um tipo de metodologia específica, sendo encontradas tanto investigações de ordem qualitativa como quantitativa, existindo, ainda, alguns pesquisadores que fazem uso de ambas as abordagens. Contudo, um dos instrumentos mais utilizados com essa finalidade tem sido a técnica dos grupos focais.

\section{Percurso metodológico}

A presente pesquisa utilizou a abordagem metodológica de ordem qualitativa, pois seu objetivo não foi mensurar o fenômeno "doença dos nervos", mas, sim, entender o que as pessoas, usuárias de psicofármacos e que freqüentam postos de saúde no Município de Santa Cruz do Sul, pensam sobre essa doença. Como nos mostram Víctora, Knauth e Hassen (2000), essa abordagem é capaz de propiciar um conhecimento aprofundado dessa questão, colaborando para melhor compreensão desse fenômeno.

A coleta de dados foi materializada através da técnica do grupo focal, pois objetivou-se identificar opiniões, sentimentos, formas de pensar, entender e interpretar a realidade por parte de pessoas nela envolvidas (Romero, 2000). Ao valer-se de grupos focais, obtiveramse resultados significativos em termos de interação grupal e insight, pois essa técnica de pesquisa qualitativa concede aos seus participantes uma profícua discussão sobre o tema em questão.

Utilizou-se um diário de campo para anotar todas as observações da pesquisadora e das colaboradoras sobre a realidade pesquisada. Berger, Morettin e Braga Neto (1994) revelam que a importância de se valer dessa técnica está na possibilidade de se registrar uma quantidade significativa de situações e vivências não registráveis em outros momentos ou outras formas de atividade.

Guareschi (2000) afirma que investigações acerca das representações sociais são muito importantes no trabalho com comunidades. Elas 
são saberes práticos e, portanto, para investigálos, é das práticas cotidianas que devemos nos valer, pois o campo representacional será desvelado através da relação entre a fala e a ação.

A pesquisa teve início no Bairro Bom Jesus, em 2003, e, em 2004, iniciou-se na vila Margarida Aurora. Para a configuração dos grupos, foram feitos chamamentos individualizados, através de visitas domiciliares e fixação de cartazes em ambos os postos de saúde. Para tanto, contamos com a participação das agentes comunitárias e das estagiárias de Psicologia comunitária de ambos os postos.

O primeiro encontro, nos dois bairros, foi para a apresentação da pesquisa, explicando-se os objetivos da mesma. Foi efetuada, a seguir, a leitura e a explicação do Termo de Consentimento Livre e Esclarecido, para, a seguir, após a anuência dos participantes, efetuar-se a assinatura dos mesmos, em duas vias, uma que ficou com o pesquisado e outra que será guardada junto aos dados coletados e incinerada após cinco anos.

Nos outros cinco encontros, foi realizada a investigação propriamente dita através dos grupos focais. Os grupos duravam aproximadamente uma hora e trinta minutos, com cerca de dois a doze participantes, que tinham como queixa, para o uso de psicofármacos, o fato de sofrerem "dos nervos". Os encontros aconteceram no próprio posto de saúde, foram gravados e, posteriormente, transcritos para checagem das informações pelo grupo, servindo-se, assim, de alavanca para as próximas discussões. Após a realização dos grupos, analisou-se o material coletado através da técnica de análise de conteúdo (Bardin, 2002).

\section{Análise e discussão dos resultados}

Foi possível perceber que a representação da "doença dos nervos" em algum momento tem um significado compartilhado pelas duas comunidades pesquisadas, o que não quer dizer que as comunidades sejam iguais na forma de pensar e sentir. Cabe aqui mencionar Moscovici (1961), estudioso das representações sociais, que as define como um conjunto de conceitos, proposições e explicações originadas na vida cotidiana em meio às comunicações interpessoais.

Nessa mesma perspectiva, Dimenstein (1997) coloca que se pode entender, por representações sociais, as idéias, imagens, concepções e percepções que as pessoas têm acerca da realidade e que estão, necessariamente, vinculadas à prática social.

Encontramos, em nossos resultados, várias representações sobre essa doença, como a crença de que a "pessoa não é mais a mesma", "que não consegue mais fazer as coisas do seu dia a dia", que transforma o seu comportamento "tornando-se criança novamente", ou seja, tudo isso reflete o estranhamento da pessoa em relação a ela mesma.

As representações sociais estão imersas no cotidiano das pessoas de forma visceral, e isso nos concede uma fonte de pesquisa riquíssima. Elas, conforme Arruda (2000), não são apenas tributárias ao passado, mas passagens para o futuro, futuro esse que nos inquieta enquanto pesquisadoras e que nos empurra a compreender o que pensam, sobre a "doença dos nervos," as pessoas portadoras desse sofrimento.

Ao se refletir sobre as causas da doença, urge pensar na sociedade e na cultura em que esse sujeito está inserido, compreendendo-se, assim, a doença como uma vivência única e subjetiva que dá origem a "implicações clínicas da relação entre a doença e a cura, e entre a sociedade e a cultura" (Silveira, 2000, p.19). As causas que as pessoas nos trouxeram ao longo dos grupos focais para essa doença foram as mais diversas, tais como doenças físicas, depressão, falta de trabalho, perdas 
significativas, solidão, problemas familiares, a violência, dificuldades de acesso ao SUS e também dificuldades de acesso ao transporte coletivo.

Cabe salientar que as causas apontadas pelas pessoas residentes no bairro Bom Jesus estão relacionadas às questões de ordem econômica e social, o que é reflexo do contexto onde estão inseridas. Conforme Campos (1994), o crescimento econômico não só favorece a necessidade de investimento em saúde como é o causador de más condições de vida e de adoecimento da população.

Dessa forma, consideramos que não existe ser humano desvinculado da sociedade, além de o seu pensamento não poder ser dissociado daquilo que ele produz (Guareschi, 2000). O sofrimento psíquico é resultado de diferentes situações históricas, conforme Dittrich (1998), e pode causar distintas reações.

Os sintomas trazidos pelos participantes das duas comunidades pesquisadas em relação ao que significa a "doença dos nervos" são bastante diversificados, surgindo a agressividade, a insônia, a irritação, o isolamento, a ansiedade, a tristeza, a falta de desejo sexual e a tentativa de suicídio como maneiras de expressar sua doença. O relato dessas pessoas revela que, quando estão envolvidas por esses sintomas, possuem um certo estranhamento consigo mesmas, preferindo permanecer isoladas. Essa talvez seja uma das razões pelas quais as pessoas busquem o suicídio, mesmo estando acompanhadas de medicação, grupos de apoio e religião.

Quanto ao sintoma insônia, trazido pelas pessoas pesquisadas em ambas as comunidades, tem o que Kaplan, Sadok e Grebb (1997) chamam de dificuldade para iniciar ou manter o sono. Essa foi uma colocação bastante presente nas falas dessas pessoas quando expressavam o seu sofrimento. Algumas delas expuseram que a irritabilidade as deixava predispostas a ficarem afastadas das outras pessoas. A esse respeito, Bleuler, citado por Paim (1993), faz considerações sobre a irritabilidade como uma predisposição especial ao desgosto, à ira e ao furor, e que as pessoas tomadas por esses sentimentos voltam a agressividades contra si mesmas.

A busca de alívio dos sintomas relacionados à "doença dos nervos" é outra característica encontrada entre as pessoas pesquisadas. Durante o trabalho de pesquisa, através da coleta de dados, pôde-se verificar que as formas de buscar o alívio para esse sintoma vão desde: ir ao CAPS, buscar auxílio médico e medicação, fumar cigarro, ouvir rádio, tomar chimarrão, sair de casa para caminhar, dançar, conversar com alguém, trabalhar em casa ou fora desta bem como participar de grupos terapêuticos. Há, portanto, uma busca de meios individuais e de ordem subjetiva que atuem tanto no corpo quanto na psique, minimizando o sofrimento, como referencia Bezerra Jr. (1989).

Assim como Dimenstein (2000) em sua pesquisa com classes populares, em nosso estudo, verificamos que os sintomas se materializam no corpo, que é o principal veículo de comunicação de suas vivências.

Constatamos, assim, que há um predomínio muito grande da prescrição de medicamentos como principal estratégia para a minimização do sofrimento psíquico. Além disso, conforme Goidanich (2001), apesar da grande multiplicidade de questões que surgem sob o nome de "doença dos nervos", é comum o fato de que o pedido daqueles que sofrem seja o de cura rápida, através da medicação.

Os sentimentos manifestados pelas pessoas em relação aos sintomas da doença nos fizeram refletir que essas pessoas percebem que a "doença dos nervos" não é igual à doença física apesar das queixas sobre o físico, pois elas buscam, no meio cultural, social e religioso, algo que thes dê sentido de vida, que ressignifique o seu cotidiano, tornando-as menos sofridas. 
... pudemos observar, em nossos resultados, que as formas como as pessoas enfrentam sua doença está relacionada com os tipos de apoio a que possuem acesso, ou seja, elas buscam apoio na família, na religião, no trabalho, em

grupos de apoio ou até mesmo passeando.
Quanto à religião, pode-se perceber que as pessoas são possuidoras de uma crença em Deus, e que, em alguns momentos, elas a tomam como elemento que, de uma certa forma, dará norte à sua vida. Taussig (1980), apud Rabelo (1994), diz que o tratamento religioso visa a agir sobre o individuo como um todo, reinserindo-o como sujeito em um novo contexto de relacionamento.

Já em relação ao trabalho como forma de a pessoa enfrentar a doença, elas colocam que o trabalho nem sempre é buscado por elas como suporte econômico para suas vidas. Segundo o relato dessas pessoas, o trabalho concede a elas o sentido de estar produzindo enquanto sujeito na relação com o mundo. Referente a isso, Dejours, Abdoucheli e Jayet (1994) argumentam que um trabalho livremente escolhido ou organizado oferece, geralmente, vias de descarga mais adaptadas às necessidades. Dessa maneira, o trabalho torna-se, então, um meio de relaxamento, às vezes a tal ponto que, ao ver a tarefa terminada, o trabalhador se sente melhor que antes de tê-la iniciado.

Uma outra forma que as pessoas apontaram para aliviar sua doença foi a dança. Segundo Hanna (1999), a dança reverbera a experiência passada, presente e habilita a mente a apoderarse desses sentimentos e idéias; além de gerar vida, possui um poder milagroso e mágico, proporcionando um sentimento de prazer e de alívio.

Após essa reflexão, pudemos observar, em nossos resultados, que as formas como as pessoas enfrentam sua doença está relacionada com os tipos de apoio a que possuem acesso, ou seja, elas buscam apoio na família, na religião, no trabalho, em grupos de apoio ou até mesmo passeando. Aqueles que têm a possibilidade de dividir o seu sofrimento e buscar alternativas para enfrentá-lo, o fazem. Aqueles que estão mais sozinhos apontam a força interna como forma de enfrentamento da sua doença e, muitas vezes, não conseguindo fazê-lo sozinhos, tentam o suicídio como alternativa para o fim do seu sofrimento.

\section{Considerações finais}

Foi possível identificar que a representação da "doença dos nervos" possui um significado compartilhado pelas duas comunidades pesquisadas - o que não significa igualdade, pois não se descarta a singularidade das pessoas ao passo que as causas, os sintomas e as formas de amenizar esses sintomas apresentam certa homogeneidade. Eles se repetem nas falas dos participantes do grupo, ao mesmo tempo em que uns se identificam com a fala dos outros. Evidente é que essa doença envolve seus portadores em causas físicas e psíquicas ao mesmo tempo, resultando numa fusão entre o corpo e a mente.

Percebeu-se, ao longo da pesquisa, que os encontros do grupo se constituíram em um espaço de troca de experiências e sentimentos entre os participantes, ao passo que os mesmos abriram caminho para as falas. Os participantes chegaram a verbalizar o quanto se sentiam melhor em poder conversar sobre o mal que os aflige ao saber que outras pessoas também passam por experiências muito semelhantes às suas. Os profissionais dos postos de saúde, pelo simples fato de perceberem que alguém estava escutando os "doentes dos nervos", passaram a ver essas pessoas (que buscam atendimento e "receitas azuis" no local) como alguém que não é puro corpo, mas que possui sentimentos, emoções, ou seja, uma dimensão psíquica que repercute na sua condição de saúde.

A pesquisa suscitou a abertura de um novo espaço nesses serviços de saúde para se discutir a questão da saúde mental, sendo que somente esse motivo já seria suficiente para justificar a realização da pesquisa. Dessa forma, constatouse que são de suma importância os estudos e pesquisas regionais, pois apontam diferenças culturais de relevância científica. Eis como a diversidade de realidades sociais interfere na concepção e significado da "doença dos nervos" e nos mostra características de determinadas populações, realidades e contextos. 
ALMEIDA, Â. M. O.; SANTOS, M. F. S.; TRINDADE, Z. A. Representações e Práticas Sociais: Contribuições Teóricas e Dificuldades Metodológicas. In Temas em Psicologia, v. 8, no 3. São Paulo: Sociedade Brasileira de Psicologia de Ribeirão Preto, 2000, pp. 257-267.

ALVES, P. C.; MINAYO, M. C. S. (org.). Doença e Saúde-um Olhar Antropológico. Rio de Janeiro: FIOCRUZ, 1994.

ARRUDA, Ângela. Mudança e Representação Social. Temas em Psicologia, v. 8, no 3. São Paulo: Sociedade Brasileira de Psicologia de Ribeirão Preto, 2000, pp. 241-247.

BARDIN, Laurence. Análise de Conteúdo. Lisboa: Edições 70, 2002.

BERGER, E; MORETTIN, A.V.; BRAGA NETO, L. Introdução à Clínica do Acompanhamento Terapêutico - I. História. In Equipe de Acompanhantes Terapêuticos do Hospital Dia A CASA (org). A Rua como Espaço Clínico: Acompanhamento Terapêutico. São Paulo: Escuta, 1991.

BEZERRA JÚNIOR, Benilton Carlos. Uma Encruzilhada Cultural: entre o Espiritual e o Nervoso. Psicologia: Ciência e Profissão, no 2. BrasiliaDF: Conselho Federal de Psicologia, 1989, pp.7-8.

CAMARGOS, Suzana Márcia Braga. Psicologia Comunitária. Caderno de Psicologia, v. 1, no 2. Belo Horizonte, dez. 93, pp. 83-91.

CAMPOS, Gastão Wagner de Souza. A Saúde Pública e a Defesa da Vida. São Paulo: HUCITEC, 1994.

DEJOURS, C.; ABDOUCHELI E.; JAYET, C. Psicodinâmica do Trabalho: Contribuições da Escola Dejouriana à Análise da Relação Prazer, Sofrimento e Trabalho. São Paulo: Atlas, 1994.

DIMENSTEIN, Magda. Representações de Maternidade de Pacientes e Terapeutas: Questões para a Prática da Psicologia nos Serviços Públicos de Saúde de Teresina - PI. In Zanella, Andréa Vieira et al. Psicologia e Práticas Sociais. Porto Alegre: ABRAPSOSUL, 1997.

A Cultura Profissional do Psicólogo e o Ideário Individualista: Implicações para a Prática no Campo da Assistência Pública à Saúde. Estudos de Psicologia, v. 5, no 5. Departamento de Psicologia. Natal: UFRN, EDUFRN, jan./jun. 2000, pp. 95 - 121.

DITTRICH, Alexandre. Psicologia, Direitos Humanos e Sofrimento Mental: Ação, Renovação e Libertação. Psicologia: Ciência e Profissão, ano 18, no 1. Brasília-DF: Conselho Federal de Psicologia: jan.1998, pp. 46-55.

GOIDANICH, Márcia. Saúde Mental na Rede Pública: Possibilidade de Inserção Psicanalítica? Psicologia: Ciência e Profissão, ano 21, no 4. Brasília-DF: Conselho Federal de Psicologia, 2001, pp. 26-33.

GUARESCHI, Pedrinho. Representações Sociais: Avanços Teóricos e Epistemológicos. Temas em Psicologia, v.8, no-3. Sociedade Brasileira de Psicologia. Sociedade Brasileira de Psicologia. Ribeirão Preto, São Paulo, 2000, pp. 249-256.

HANNA, Judith Lynne. Dança, Sexo e Gênero: Signos de Identidade-Dominação, Desafio e Desejo. Rio de Janeiro: Rocco, 1999.

JODELET, D. Représentation Sociale: Phenomène, Concept et Théorie. In Moscovici, Serge, (org.), Psychologie Sociale. Paris : Presses Universitaires de France, 1984, pp. 357-378.

KAPLAN, H.; SADOK, B. J.; GREBB, J. A. Compêndio de Psiquiatria: Ciências do Comportamento e Psiquiatria Clínica. Porto Alegre: Artes Médicas, 1997.

LEITE, Sônia. O Psicólogo e algumas Práticas no Serviço Público Estadual de Saúde. Conselho Federal de Psicologia. Psicologia: Ciência e Profissão, 17(1). Brasília-DF, 1997, pp. 35-39.

LHULLIER, Louise A. A Psicologia Política e o Uso da Categoria "Representações Sociais" na Pesquisa do Comportamento Político. In Zanella, Andréa Vieira et al. Psicologia e Práticas Sociais. Porto Alegre: ABRAPSOSUL, 1997.

MOSCOVICI, S. ; HEWSTONE, M. De la Science au Sens Commun. In Moscovici, Serge (org.), Psychologie Sociale. Paris : Presses Universitaires de France, 1984, pp.536-558.

MOSCOVICI, S. La Psychanalyse, son Image, son Public. Paris: Presses Universitaires de France, 1961.

OLIVEIRA, F. O.; WERBA, G. C. Representações Sociais. In Jacques, Maria da Graça Corrêa et al. Psicologia Social Contemporânea. Petrópolis, Rio de Janeiro: Vozes, 1998.

PAIM, Isaías. Curso de Psicopatologia. São Paulo: EPU, 1993.

RABELO, Miriam Cristina M. Religião, Ritual e Cura. Trabalho apresentado no I Encontro Nacional de Antropologia Médica, Salvador (BA), 3 a 6 de novembro de 1993. In Alves, Paulo César (org). Saúde e Doença: um Olhar Antropológico. Rio de Janeiro: FIOCRUZ, 1994.

ROMERO, Sonia Mara. A Utilização da Metodologia dos Grupos Focais na Pesquisa em Psicologia. In Scarparo, Helena (org). Psicologia e Pesquisa: Perspectivas Metodológicas. Porto Alegre: Sulina, 2000.

SILVEIRA, Maria Lúcia da. O Nervo Cala, o Nervo Fala: a Linguagem da Doença. Rio de Janeiro: FIOCRUZ, 2000.

VÍCTORA, C. G.; KNAUTH, D. R.; HASSEN, M. N. A. A Pesquisa Qualitativa em Saúde. Porto Alegre: Tomo Editorial, 2000.

WEIGELT, Leni. O Sistema Único de Saúde e os Profissionais da Saúde de Nível Universitário da Rede Pública de Santa Cruz do Sul-RS. Santa Cruz do Sul: EDUNISC, 2001.
Referências 